\title{
DAMPAK PERUBAHAN IKLIM TERHADAP IMBANGAN AIR SECARA METEOROLOGIS DENGAN MENGGUNAKAN METODE THORNTHWAITE MATHER UNTUK ANALISIS KEKRITISAN AIR DI KARST WONOGIRI
}

\author{
Oleh: \\ Pipit Wijayanti ${ }^{1}$, Rita Noviani ${ }^{1}$, Gentur Adi Tjahjono ${ }^{1}$ \\ ${ }^{1}$ Prodi P. Geografi FKIP Universitas Sebelas Maret Surakarta \\ Email: pipitkusuma@gmail.com
}

\begin{abstract}
Abstrak
Perubahan Iklim Global juga dirasakan di Indonesia. Berdasarkan data curah hujan antara 1978-2005 telah terjadi kecenderungan penurunan curah hujan dengan peningkatan suhu sebesar 0,04 - 0,047 $\mathrm{C} /$ tahun. Karst Wonogiri yang terletak di Kabupaten Wonogiri selalu mengalami masalah tahunan berupa kekeringan di musim kemarau. Penelitian ini berjudul Dampak Perubahan Iklim terhadap Neraca Air Secara Meteorologi dengan Metode Thornthwaite-Mather untuk Analisis Kekritisan Air di Karst Wonogiri. Tujuan penelitian ini adalah: 1). mengetahui kondisi curah hujan tahunan selama perubahan iklim di Karst Wonogiri, 2). mengetahui nilai kemampuan menahan air/Water Holding Capacity (WHC) di Karst Wonogiri, dan 3). menganalisis neraca air secara meteorologis berdasarkan metode Thornthwhite Matter di Karst Wonogiri. Metode analisis imbangan air yang digunakan adalah Thorthwaite Mather untuk menentukan ketersediaan air. Hasil penelitian yang diperoleh adalah: (1) Kondisi curah hujan tahunan di Karst Wonogiri masih termasuk kategori sedang, dengan tebal hujan tahunan bisa mencapai $2000 \mathrm{~mm}$. Fluktuasi curah hujan tahunan tidak terlalu ting gi (200$500 \mathrm{~mm}$ per tahun); (2) Perhitungan nilai WHC sebesar 112,92 menunjukkan bahwa kemampuan lahan di wilayah penelitian untuk menyimpan dan mengikat air termasuk rendah yang disebabkan oleh jenis tanah yang ada memiliki solum tanah dangkal hingga sedang serta struktur tanah kersai dan pasiran. Jenis vegetasi penutup yang berupa palawija dengan zone parakaran dangkal juga mempengaruhi besarnya nilai WHC; (3) Analisis neraca air secara meteorologis dapat disimpulkan bahwa ketersediaan air dari curah hujan di wilayah ini termasuk cukup tinggi dengan 7-8 bulan yang surplus. (4) Indeks kekritisan air sebesar 0,56 termasuk dalam kategori mendekati kritis
\end{abstract}

Kata kunci: Perubahan iklim, imbangan air

\section{PENDAHULUAN}

Air merupakan salah satu unsur sumberdaya alam dan kebutuhan pokok makhluk hidup agar dapat mempertahankan kelangsungan hidup secara hayati. Keberadaan air di bumi secara kuantitatif persebarannya terbatas baik secara keruangan, maupun menurut waktu. Secara keruangan karena potensi ketersediaan air di tempat yang satu berbeda dengan tempat yang lain tergantung pada karakteristik lahannya. Keterbatasan menurut waktu adalah kuantitas air dari waktu ke waktu tidak sama jumlahnya.

Presipitasi merupakan sumber pasokan air di permukaan bumi yang akan didistribusikan sesuai dengan siklus air. Sebagai sumber poasokan air, maka presipitasi 
Dampak Perubahan Iklim Terhadap Imbangan Air Secara Meteorologis Dengan Menggunakan Metode Thornthwaite Mather Untuk Analisis Kekritisan Air di Karst Wonogiri

sangat penting untuk keberlangsungan keberadaan air di permukaan bumi. Akan tetapi perubahan iklim global telah berpengaruh terhadap kuantitas dan distribusi air hujan.

Perubahan iklim global ditandai dengan peningkatan suhu sebagai akibat dari peningkatan aktifitas manusia.. Tercatat sejak abad ke-19 suhu permukaan bumi telah mengalami peningkatan sekitar $0,8^{\circ} \mathrm{C}$. Peningkatan suhu diperkirakan sekitar $0,15^{\circ} \mathrm{C}$ sampai $0,3^{\circ} \mathrm{C}$ setiap dekade sejak tahun 1990-2005 (IPCC/Intergovernmental Panel on Climate Change, 2007). Perubahan iklim ini memberi dampak negatif bagi kehidupan manusia (Ratag, 2008), diantaranya adalah tren peningkatan curah hujan yang dilaporkan di Argentina (Viglizzo dkk, 1995), trend penurunan curah hujan yang menyebabkan kekeringan di, Afrika (Mason, 1996), China (Zhai et al, 1999), dan di Iran (Marsoudi dan Afrough, 2011).

Dampak perubahan iklim juga dirasakan di Indonesia. Kecenderungan penurunan curah hujan secara umum terjadi di Indonesia (Dipayana, dkk, 2012). Berdasarkan data curah hujan dan suhu tahun 1978-2005 telah terjadi kecenderungan penurunan curah hujan di Gunungkidul dengan peningkatan suhu sebesar 0,04-0,047 C/th (Sudarmadji, dkk, 2012).

Kabupaten Wonogiri bagian selatan merupakan bentuklahan karst. Bentuklahan karst terbentuk karena proses pelarutan dengan batuan penyusun berupa batugamping (limestone). Pada dasarnya batugamping berpotensi menyimpan airtanah karena mempunyai banyak rekahan dan permeabilitas sekunder. Akan tetapi karena letaknya yang dalam, maka penduduk mengalami kesulitan mengeksploitasi untuk kebutuhan sehari-hari. Hal ini yang menyebabkan daerah karst identik dengan kekeringan.

Perhitungan neraca air secara meteorologis, diperlukan untuk mengetahui potensi sumberdaya air yang dapat dimanfaatkan oleh penduduk sekitar. Terlebih dampak perubahan iklim yang menjadikan musim hujan dan kemarau yang tidak tentu. Potensi air yang merupakan ketersediaan air ini yang akan digunakan untuk menentukan indeks kekritisan air.

Kabupaten Wonogiri bagian selatan merupakan bentuklahan karst yang berpotensi menyimpan airtanah akan tetapi pada kenyataannya selalu mengalami kekeringan. Kekeringan selalu menjadi masalah tahunan di Kabupaten Wonogiri, khususnya bagian selatan (Suara merdeka, Oktober 2011). Kekeringan sudah mulai terjadi akhir bulan Mei pada tahun 2012 di Kecamatan Giritontro, Paranggupito dan Pracimantoro (Harian Jogja, Juni 2012). Curah hujan yang cenderung menurun tentunya akan mempengaruhi pasokan air di Wonogiri bagian selatan, sehingga ketersediaan air untuk penduduk semakin berkurang. Pada daerah karst ini dampak perubahan iklim sangat terasa. Sehingga perlu adanya penelitian neraca air secara meteorologi sebagai dasar untuk mentukan indeks kekritisan air.

Berdasarkan beberapa penelitian yang telah dilakukan, metode perhitungan ketersediaan air secara meteorologis merupakan metode yang cukup akurat dalam menentukan besarnya ketersediaan air. Ketersediaan secara meteorologis adalah jumlah air yang jatuh ke permukaan bumi dikurangi dengan evapotranspirasi dan koefisien aliran $(\Delta S=(P-E a)(1-C)$. Kekritisan air pada dasarnya merupakan perbandingan antara ketersediaan dengan kebutuhan. 
Bertolak pada hal tersebut, maka timbul pertanyaan, yaitu:

1. Bagaimana kondisi curah hujan tahunan pada masa perubahan iklim di Karst Wonogiri?

2. Bagaimana nilai kemampuan menahan air/Water Holding Capacity (WHC) di Karst Wonogiri?

3. Bagaimana imbangan air secara meteorologis berdasarkan metode Thorntwhite Matter di Karst Wonogiri?

4. Bagaimana Indeks kekritisan air di Karst Wonogiri?

\section{KAJIAN PUSTAKA}

\section{Bentuklahan Karst dan Proses Pelarutan}

Karst merupakan suatu kawasan yang mempunyai karakteristik relief dan pengaktusan (drainase) yang khas terutama disebab oleh derajad pelarutan batuan di dalam air yang lebih tinggi dibandingkan dengan tempat lain (Sweeting, 1972, Jennings 1971, Ford dan Williams 1989). Syarat yang harus terpenuhi untuk terbentuknya karst menurut Ritter (tahun 1979) adalah terdiri dari batugamping (limestone) yang murni, masif, keras dan kristalin; ketebalan lebih dari seratus meter; berlapis baik dan banyak rekahan serta tereksresi oleh relief di atas permukaan lereng yang tinggi, sehingga dapat memudahkan sistem sirkulasi.

Proses utama yang terjadi di dalam topografi karst adalah pelarutan. Terdapat dua hal pokok dalam proses pelarutan, yaitu unsur pelarut dan batuan terlarut. Unsur pelarut berasal dari air terutama air hujan, sedangkan unsur terlarut berupa batuan yang mudah larut seperti batugamping (Bloom, 1979). Menurut Ritter (tahun 1979) unsur kimia penting yang mempengaruhi Proses pelarutan adalah kadar-kadar karbon dioksida $\left(\mathrm{CO}_{2}\right)$ dalam air hujan. Karbon dioksida yang terlarut akan membentuk asam karbonat $\left(\mathrm{H}_{2} \mathrm{CO}_{3}\right)$. Reaksi kimia proses pelarutan adalah sebagai berikut:

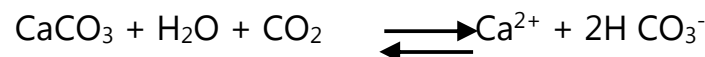

Semua reaksi yang berjalan meupakan reaksi keseimbangan, sehingga arah jalannya dapat berbalik (reversib/e). Hal ini menyebabkan perubahan suatu kondisi dapat mempengaruhi rekasi-reaksi selanjutnyn. Keseimbangan kalsit tergantung pada temperature, tekanan $\mathrm{CO}_{2}$ dan ketebalan akuifer dan kedalaman air (Z. Liu dan W. Dreybrodr, 1997). Setiap pelarutan 1 ton batuan karbonat $\left(\mathrm{CaCO}_{3}\right)$ memerlukan $120 \mathrm{~kg}$ karbon yang diambil dari $\mathrm{CO}_{2}$ di atmosfer (Yuan, 2003). Ziu Liu dan J. Zhao (1999) memperkirakan bahwa potensi $\mathrm{CO}_{2}$ yang dapat diserap oleh batuan karbonat di dunia rerata sebesar 0,3. milyar metric ton/area. Besarnya $\mathrm{CO}_{2}$ yang terserap ini berdasarkan hasil penelitian di China. $\mathrm{CO}_{2}$ terserap bersih sebesar 0,72334 Pg karbon/area (Z. Liu, W. Dreybrodt dan Haijing Wang, 2010), dimana 1 Pg sebanding dengan 1 trilyun metric ton.

Karst mempunyai sistem drainase yang spesifik. Air karst merupakan air permukaan atau air tanah dengan kualitas kimia yang menggambarkan aktivitas dalam pemecahan karbonat selama perjalanan sampai outlet oleh sebuah massa/singkapan batugamping massif (Pitty dalam Sweeting, 1972). Larutan $\mathrm{CaCO}_{3}$ pada air dari limestone berbeda-beda yang selalu menunjukkan pola yang jelas, dalam arti bahwa larutan yang ada adalah murni, yaitu tidak ada material lain dan air karst hamper tidak mempunyai endapan 
Dampak Perubahan Iklim Terhadap Imbangan Air Secara Meteorologis Dengan Menggunakan Metode Thornthwaite Mather Untuk Analisis Kekritisan Air di Karst Wonogiri

alluvium (Sweeting, 1972). Sejak tahun 1992 - 2005 konsentrasi $\mathrm{CO}_{2}$ meningkat sebesar 7\% (GL, Macpherson, dkk, 2008). Hal ini menunjukkan bahwa airtanah dangkal pada karst bertindak sebagaipenyerap $\mathrm{CO}_{2}$.

Sistem drainase epikarst adalah satu dari tiga drainase yang ada di daerah karst. Sistem drainase karst mempunyai simpanan dan daya hantar air besar (Sater, 1997). Simpanan air di drainase epikarst terletak di ruang pelarutan, rekahan yang melebar karena pelarutan dan pori-pori antar butir material endapan. Permeabilitas di mintakat epikarst terbesar berturut-turut disela-sela antara batugamping dan material endapan, saluran yang saling berhubungan dan permeabilitas antar butir (Huntin, 1992)

\section{Neraca Air dan Faktor yang Mempengaruhinya}

Neraca air secara umum adalah hubungan antara aliran masuk dengan aliran keluar di suatu wilayah untuk suatu periode tertentu (Sosrodarsono, 1997). Neraca air menurut fungsi meteorologis diperlukan untuk mengevaluasi ketersediaan air hujan di suatu wilayah, terutama untuk mengetahui kapan dan seberapa surplus serta defisit yang terjadi di wilayah yang ditinjau. Subiyakto (1985) mengemukakan bahwa dalam perkembangannya timbul banyak persamaan neraca air, seperti persamaan umum Hounem et al., persamaan air oleh Thornthwaite dan Mather (1957), persamaan air oleh Chang dan persamaan air lapang untuk keperluan irigasi oleh Doorenbos dan Proit.

Namun demikian yang paling banyak digunakan adalah persamaan neraca air oleh Thornthwaite dan Mather. Asumsi yang digunakan dalam metode ini yaitu, semua air hujan dapat mengisi airtanah. Air hujan yang jatuh digunakan untuk memenuhi kebutuhan evapotranspirasi, sedangkan kelebihan yang lain akan disimpan dalam cadangan air di dalam tanah. Asumsi yang kedua adalah jika simpanan air dalam tanah telah mencapai batas maksimal, maka kelebihan air akan dihitung sebagai surplus, dan surplus ini akan dikeluarkan dalam bentuk aliran permukaan. Persamaan metode Thornthwaite dan Mather dapat dirumuskan sebagai berikut:

$P=E t+d s+R o$

Dimana:

$\mathrm{P}=$ presipitasi (curah hujan), Et $=$ evapotranspirasi, $\mathrm{Ds}=$ perubahan cadangan air dalam tanah, Ro = limpasan

Berdasarkan rumus tersebut, maka diketahui bahwa neraca air suatu daerah sangat dipengaruhi oleh curah hujan, evapotranspirasi dan perubahan cadangan air dalam tanah. air suatu daerah sangat dipengaruhi oleh curah hujan, evapotranspirasi dan perubahan cadangan air dalam tanah. Perubahan cadangan air dalam tanah ini sangat tergantung pada Water Holding Capacity (WHC). Menurut Thornthwaite dan Mather (1957) bahwa Water Holding Capacity (WHC) dipengaruhi oleh dua faktor, yaitu tekstur tanah dan vegetasi penutup. Kedua faktor tersebut bersama-sama menentukan besarnya lengas tanah tertahan. Dimana struktur dan tekstur tanah turut menentukan tata air tanah, hal ini terkait dengan infiltrasi dan kemampuan menahan air. Sementara pada jenis vegetasi yang sama, apabila tumbuh pada macam tanah yang berbeda akan memberikan kedalaman perakaran yang berbeda. 


\section{METODE}

1). Mengetahui kondisi curah hujan tahunan selama perubahan iklim di Karst Wonogiri

Kondisi curah hujan tahunan di Karst Wonogiri dilakukan dengan kecenderungan (trend) selama minimal 10 tahun. Data yang digunakan adalah data curah hujan rata-rata bulanan. Rata-rata curah hujan bulanan dilakukan dengan melihat hujan wilayah. Perhitungan hujan wilayah dilakukan dengan menggunakan metode Poligon Thiesson, karena mempertimbangkan lokasi penelitian yang tidak rata atau bertopografi.

2). Mengetahui nilai kemampuan menahan air/Water Holding Capacity (WHC) di Karst Wonogiri

Water Holding Capacity merupakan kemampuan tanah untuk menahan air. Data yang digunakan adalah data penggunaan lahan dan tekstur tanah. Penggunaan lahan didapatkan dari analisis citra landsat dan peta RBI. Tekstur tanah diidentifikasi dengan uji sampel tanah di laboratorium. Pengambilan sampel berdasarkan pada peta macam tanah.

Tumpang susun (overlay) peta penggunaan lahan dan tekstur tanah digunakan sebagai dasar untuk menentukan besarnya kemampuan tanah menahan air (Water Holding Capacity) dengan menggunakan tabel yang telah tersedia. Tabel yang digunakan berdasarkan pada Thornthwaite dan Mather dalam Darmanto 1980. Tabel penetuan kemampuan menahan air berdasarkan kombinasi tekstur dan vegetasi disajikan pada Tabel 4.

3). Analisis neraca air secara meteorologis berdasarkan metode Thornthwhite Matter di Karst Wonogiri

Menghitung neraca air dilakukan dengan metode Thornthwaite Mather. Untuk menghitung surplus ketersediaan air dilakukan perhitungan secara berurutan mulai dari curah hujan, evaporasi potensial, akumulasi potensial dari Water loss (APWL), penimbunan air (ST), tambahan penimbunan (i1ST), evaporasi aktual, serta defisit dan surplus. Kemudian dari angka surplus dihitung berapa besar dari ketersediaan tiap bulan. Uraian mengenal tahapan dalam perhitung tersebut dapat dijelaskan sebagai berikut:

\section{Tahap 1 : Menghitung rata-rata curah hujan (P) bulanan \\ Tahap 2 : Menghitung evapotranspirasi potensia1 (EP) bulanan \\ Tahap 3 : Menghitung (P - EP) \\ Tahap 4 : Menghitung akumulasi potensial Water loss dengan menjumlahkan angka-angka ( $P$ - EP), untuk bulanan yang mempunyai angka negatif}

Tahap 5 : Menghitung SoU Moisture Storage (ST) dilihat pada Tabel WHC (Sto) pada bulan-bulan dimana APWL $=0$, sementara pada bulanbulan dimana APWL negatif, nilai ST dicari dengan menggunakan rumus:

$$
\begin{aligned}
& \text { ST }=\text { Sto.eAPWLI-Sto } \\
& \mathrm{e}=2,718 \\
& \text { Keterangan: } \mathrm{ST}=\text { nilai soil moisture storage }
\end{aligned}
$$


Dampak Perubahan Iklim Terhadap Imbangan Air Secara Meteorologis Dengan Menggunakan Metode Thornthwaite Mather Untuk Analisis Kekritisan Air di Karst Wonogiri

Tabel 4. Pendugaan Water Holding Capacity berdasarkan kombinasi tekstur tanah dan vegetasi penutup

\begin{tabular}{|c|c|c|c|}
\hline Tekstur & $\begin{array}{l}\text { Air tersedia } \\
(\mathbf{m m} / \mathbf{m})\end{array}$ & $\begin{array}{c}\text { Kedalaman } \\
\text { Perakaran (m) }\end{array}$ & $\begin{array}{l}\text { Kemampuan tanah } \\
\text { menahan air }(\mathrm{mm})\end{array}$ \\
\hline \multicolumn{4}{|c|}{ Tanaman Perakaran dangkal (bayam, kacang, wortel } \\
\hline Pasir halus & 100 & 0.50 & 50 \\
\hline Geluh pasiran & 150 & 0.50 & 75 \\
\hline Geluh debuan & 200 & 0.62 & 152 \\
\hline Geluh lempungan & 250 & 0.40 & 100 \\
\hline Lempung & 300 & 0.25 & 75 \\
\hline \multicolumn{4}{|c|}{ Tanaman Perakaran Sedang (jagung, tembakau, dII) } \\
\hline Pasir halus & 100 & 0.75 & 75 \\
\hline Geluh pasiran & 150 & 1.00 & 150 \\
\hline Geluh debuan & 200 & 1.00 & 200 \\
\hline Geluh lempungan & 250 & 0.80 & 200 \\
\hline Lempung & 300 & 0.50 & 150 \\
\hline \multicolumn{4}{|c|}{ Tanaman Perakaran Dalam (legume, padang rumput, semak belukar) } \\
\hline Pasir halus & 100 & 1.00 & 100 \\
\hline Geluh pasiran & 150 & 1.00 & 150 \\
\hline Geluh debuan & 200 & 1.25 & 250 \\
\hline Geluh lempungan & 250 & 1.00 & 250 \\
\hline Lempung & 300 & 0.67 & 200 \\
\hline \multicolumn{4}{|c|}{ Tanaman Perkebunan } \\
\hline Pasir halus & 100 & 1.00 & 150 \\
\hline Geluh pasiran & 150 & 1.00 & 250 \\
\hline Geluh debuan & 200 & 1.25 & 300 \\
\hline Geluh lempungan & 250 & 1.00 & 250 \\
\hline Lempung & 300 & 0.67 & 200 \\
\hline \multicolumn{4}{|c|}{ Hutan } \\
\hline Pasir halus & 100 & 2.50 & 250 \\
\hline Geluh pasiran & 150 & 2.00 & 300 \\
\hline Geluh debuan & 200 & 2.00 & 400 \\
\hline Geluh lempungan & 250 & 1.60 & 400 \\
\hline Lempung & 300 & 1.17 & 350 \\
\hline
\end{tabular}

Sumber: Thornthwaite dan Mather dalam Darmanto 1980 
APWL = nilai accumalation potensial waater loss

Sto $=$ nilai water holding capacity

Tahap 6 : Menghitung Change in sad moisture (i1ST) dengan cara mengurangi nilai ST pada suatu bulan dengan ST pada bulan sebelumnya.

ST I = (ST bulan ke-i) - ST sebelum bulan ke-i)

Tahap 7 : Menghitung Evapotranspirasi Aktual (EA), yaitu untuk bulan-bulan basah $(P>E P)$, maka $E A=E P$. Untuk bulan kering $(P<E P)$, maka $E A$ $=\mathrm{P}+$ liST

Tahap 8 : Menghitung Moisture Deficit (D) yaitu dengan mencari selisih untuk bulan dengan $(P<E P)$

Tahap 9 : Menghitung Moisture Surplus ( $S$ ) yaitu diperhitungkan untuk bulan dengan $(P>E P)$. Untuk $S T=$ Sto $\mathrm{mm} /$ bulan, maka $\mathrm{S}=\mathrm{P}-\mathrm{EP}$, sementara untuk ST < Sto mIT'Jbulan maka $S=(P-E P)-$ Li ST.

Tahap 10 : Menggambar neraca air dalam bentuk grafik dengan unsur-unsur yang dipakai yaitu presipitasi (P), evapotranspirasi potensial (EP), dan evapotranspirasi aktual (EA) dengan memberi legenda untuk bulan-bulan surplus, defisit dan soil moisture use

4). Indeks Kekritisan Air

Indeks kekritisan air merupakan perbandingan antara ketersediaan dengan kebutuhan. Ketersediaan air si suatu wilayahdapat diperkirakan berdasarkan surplus air tahunan dengan formulasi

$$
\mathrm{Q}=\mathrm{R} \times \mathrm{L}
$$

Dimana $\mathrm{R}$ adalah runoff tahunan (mm/th) sikonversikan ke dalam ( $\mathrm{m} /$ tahun), $\mathrm{L}$ adalah luas area (km2/ha) dikonversikan ke dalam $\mathrm{m} 2$ dan $\mathrm{Q}$ adalah besarnya ketersediaan air (m3/tahun). Kebutuhan air diasumsikan terdiri dari kebutuhandomestik dan irigasi untuk tanaman. Berdasarkan PT Indah Karya, 2003 kebutuhan air perkotaan diasumsikan $150 \mathrm{l} / \mathrm{hri}$, sedangkan penduduk perdesaan 60 I/hari. Air untuk pertanian dibedakan menjadi tanaman padi (sawah) dan palawija (tegalan). Irigasi tanaman padi diasumsikan $1 \mathrm{l} / \mathrm{ha}$ dan tanaman palawija 0,25 l/ha. Data ketersediaan dan kebutuhan air dapat digunakan untuk evaluasi mengenai cadangan air yang tersedia di suatu wilayah, yang dapat dinyatakan dengan indeks kekritisan air

$$
\text { Indeks kekritisan air }=\frac{\text { kebutuhan air }}{\text { Ketersediaan air }} \times 100 \%
$$

\section{HASIL PENELITIAN}

Kabupaten Wonogiri, dengan luas wilayah $182.236,02$ Ha secara geografis terletak pada garis lintang $7^{\circ} 32^{\prime}$ sampai $8^{\circ} 15^{\prime}$ dan garis bujur $110^{\circ} 41^{\prime}$ sampai $111^{\circ} 18^{\prime}$ dengan batas-batas sebagai berikut: sebelah Utara berbatasan dengan Kabupaten Sukoharjo dan Kabupaten Karanganyar ;sebelah Timur berbatasan dengan Kabupaten Karanganyar dan 
Dampak Perubahan Iklim Terhadap Imbangan Air Secara Meteorologis Dengan Menggunakan Metode Thornthwaite Mather Untuk Analisis Kekritisan Air di Karst Wonogiri

Kabupaten Ponorogo (Jawa Timur); sebelah Selatan berbatasan dengan Kabupaten Pacitan (Jawa Timir) dan Samudra Indonesia; dan sebelah Barat berbatasan dengan Daerah Istimewa Yogyakarta dan Kabupaten Klaten.

Secara umum daerah ini beriklim tropis, mempunyai 2 musim yaitu penghujan dan kemarau dengan temperatur rata-rata $24^{\circ} \mathrm{C}$ hingga $32^{\circ} \mathrm{C}$. Dengan topografi daerah yang tidak rata, perbedaan antara satu kawasan dengan kawasan lain membuat kondisi sumber daya alam juga saling berbeda. Di Wonogiri hampir sebagian besar tanahnya tidak terlalu subur untuk pertanian. Terutama di wilayah selatan, yang merupakan daerah karst, dicirikan dengan wilayah berbatuan dan iklim yang kering membuat penduduknya lebih banyak merantau (boro). Kawasan bentang alam karst yang ada di Wonogiri sekitar $16.544,732 \mathrm{Ha}$ dari total luas wilayah Kabupaten Wonogiri yang luasnya 182.236,0236 Ha. Kawasan karst Gunung Sewu sendiri merupakan kawasan bentang alam berupa batu gamping yang membentang dari Wonogiri (Jawa Tengah), Kabupaten Wonosari (DIY), dan Kabupaten Pacitan (Jawa Timur)

(www.wonogirikab.go.id/home.php?mode=content\&id=206).

Wilayah penelitian yang berada di Kabupaten Wonogiri ini terletak di wilayah yang berbatasan dengan Kecamatan Eromoko dan Giriwoyo (utara), Kabupaten Pacitan, Provinsi Jawa Timur (timur), Samudera Hindia (selatan) dan Kabupaten Gunung Kidul, Provinsi DIY (barat). Posisi wilayah penelitian berdasarkan proyeksi UTM adalah 472911.59 mT - $495763.48 \mathrm{mT}$ dan $9122533.37 \mathrm{mU}-9092271.99 \mathrm{mU}$.

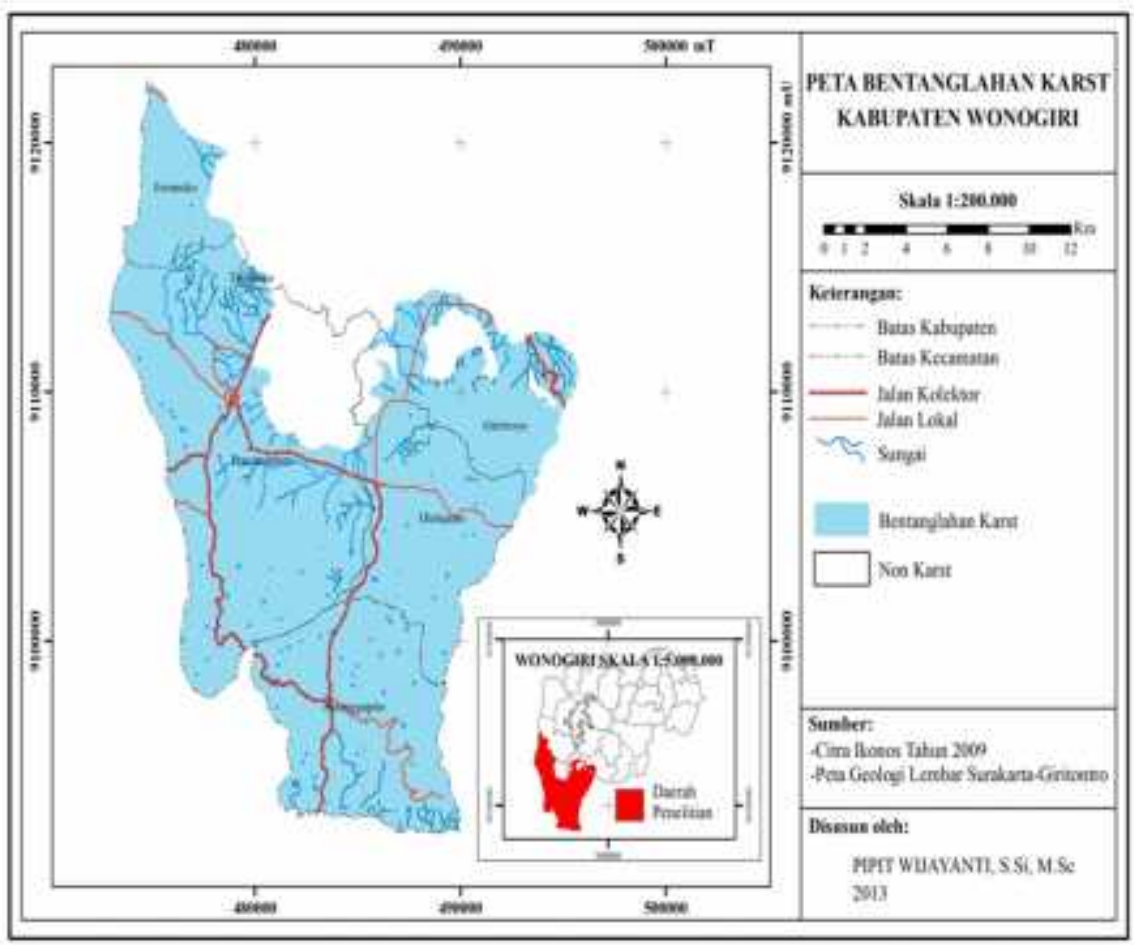

Gambar 1. Peta Bentanglahan Karst Kabupaten Wonogiri 
Hasil penelitian yang diperoleh adalah:

(1) Kondisi curah hujan tahunan di Karst Wonogiri masih termasuk kategori sedang, dengan tebal hujan tahunan bisa mencapai $2000 \mathrm{~mm}$. Fluktuasi curah hujan tahunan tidak terlalu tinggi (200-500 mm per tahun). Yang tampak nyata adalah perubahan suhu yang cukup tinggi setiap tahunnya yang menunjukkan di wilayah penelitian terkena dampak pemanasan global;

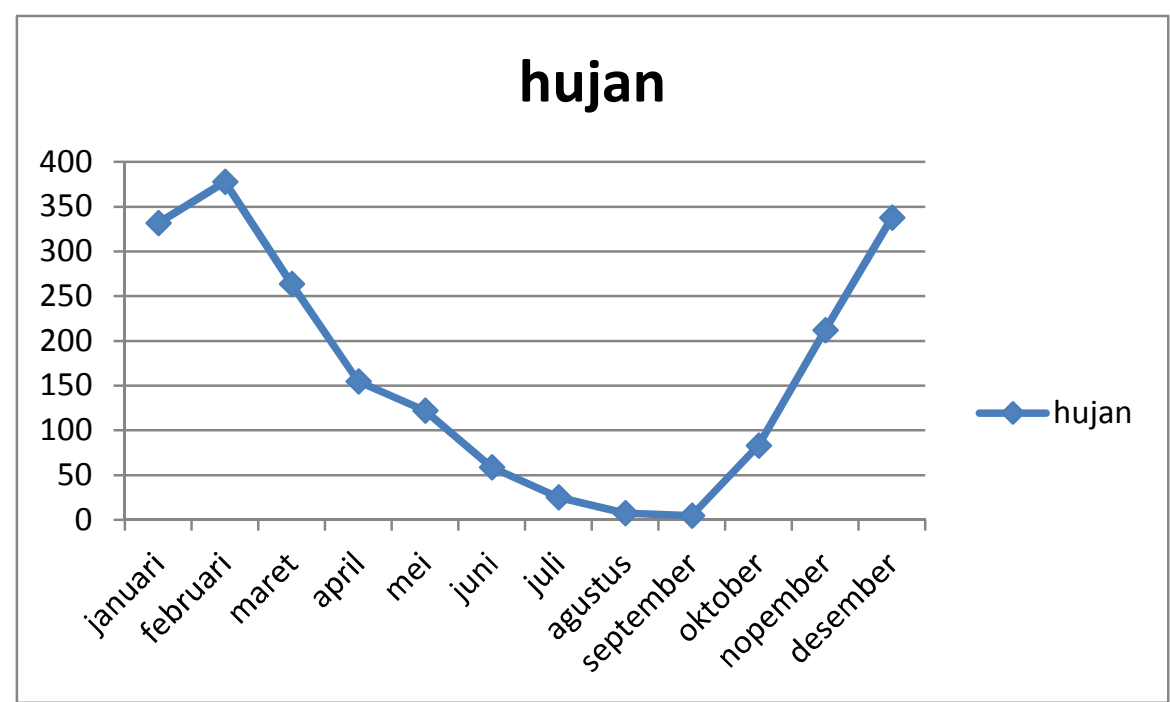

Gambar 2. Grafik Pola Curah Hujan Rerata Bulanan Tahun 2002-2012 di Wilayah Penelitian.

(2) Perhitungan nilai WHC sebesar 112,92 menunjukkan bahwa kemampuan lahan di wilayah penelitian untuk menyimpan dan mengikat air termasuk rendah yang disebabkan oleh jenis tanah yang ada memiliki solum tanah dangkal hingga sedang serta struktur tanah kersai dan pasiran. Jenis vegetasi penutup yang berupa palawija dengan zone parakaran dangkal juga mempengaruhi besarnya nilai WHC;

Tabel 1. Luas dan Prosentase Penggunaan lahan di Kabupaten Wonogiri Tahun 2012 Sumber: data primer, 2013.

\begin{tabular}{|c|l|r|r|}
\hline No & Penggunaan Lahan & \multicolumn{1}{c|}{ Luas } & \multicolumn{1}{|c|}{ Prosentase } \\
\hline 1 & permukiman & 5198.18 & 17.52 \\
\hline 2 & sawah & 3554.24 & 11.98 \\
\hline 3 & tegalan & 16740.50 & 56.42 \\
\hline 4 & kebun & 1632.55 & 5.50 \\
\hline 5 & sawah tadah hujan & 2461.65 & 8.30 \\
\hline 6 & semak belukar & 85.06 & 0.29 \\
\hline & & 29672.18 & 100.00 \\
\hline
\end{tabular}


Dampak Perubahan Iklim Terhadap Imbangan Air Secara Meteorologis Dengan Menggunakan Metode Thornthwaite Mather Untuk Analisis Kekritisan Air di Karst Wonogiri

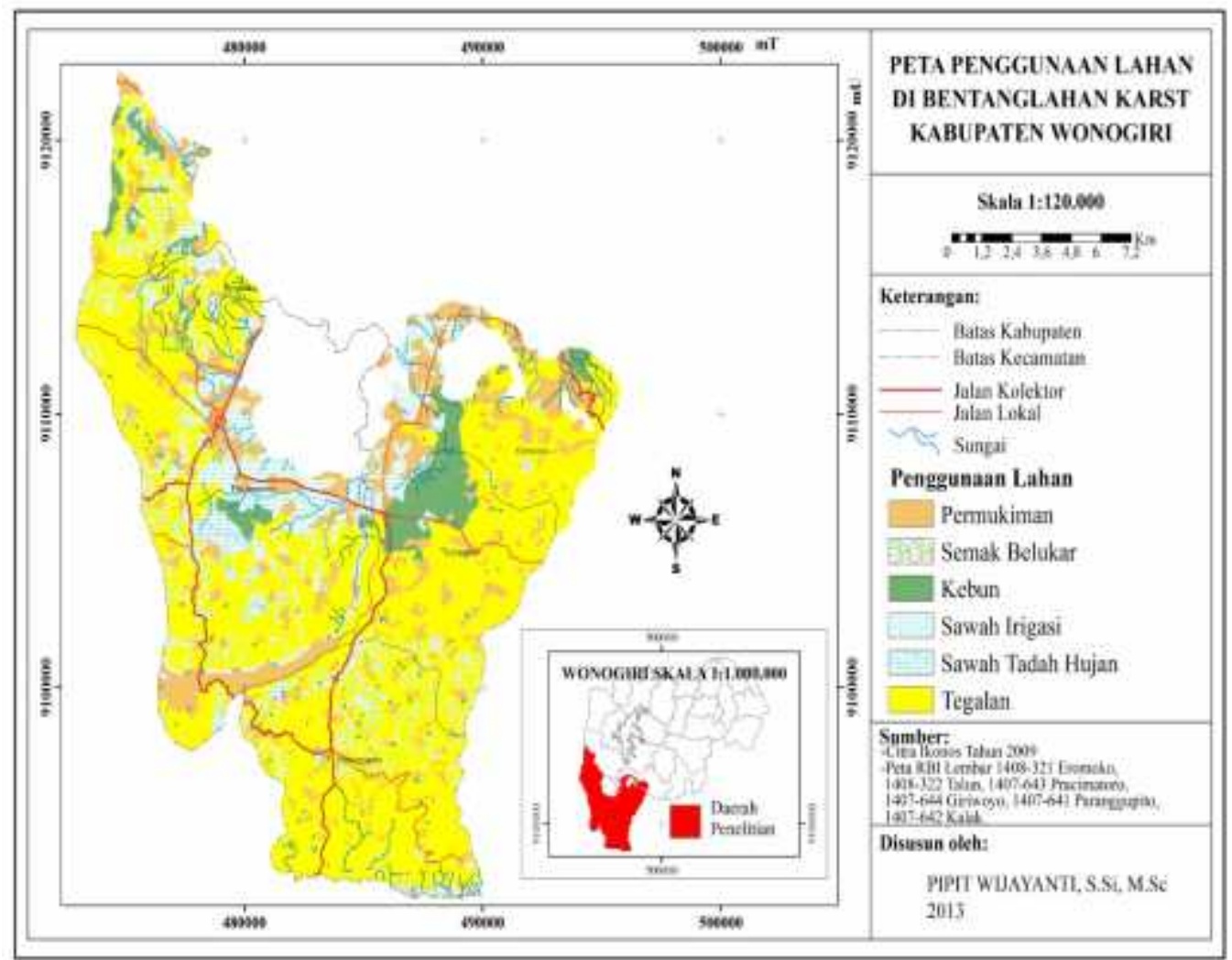

Gambar 3. Peta Penggunaan Lahan di Bentanglahan Karst Kabupaten Wonogiri

Tabel 2. Nilai WHC berdasarkan Satuan Lahan dan Luas Lahan dengan Penentuan Nilai STO di Wilayah Penelitian.

\begin{tabular}{|c|c|c|c|c|c|c|}
\hline no & Satuan Lahan & luas hektar & $\begin{array}{c}\text { luas persen } \\
\text { dari total }\end{array}$ & nilai STO & STO*\%wilayah & WHC \\
\hline 1 & gh-pmk & 336.15 & 1.13 & 0.00 & 0.00 & 0.00 \\
\hline 2 & gh-sw & 255.23 & 0.86 & 75.00 & 64.51 & 0.65 \\
\hline 3 & gh-tg & 3.29 & 0.01 & 150.00 & 1.66 & 0.02 \\
\hline 4 & klck-kb & 81.45 & 0.27 & 150.00 & 41.17 & 0.41 \\
\hline 5 & klck-pmk & 200.19 & 0.67 & 0.00 & 0.00 & 0.00 \\
\hline 6 & klck-sw & 22.61 & 0.08 & 50.00 & 3.81 & 0.04 \\
\hline 7 & klck-swtd & 27.39 & 0.09 & 50.00 & 4.61 & 0.05 \\
\hline 8 & klck-tg & 307.57 & 1.04 & 75.00 & 77.74 & 0.78 \\
\hline 9 & klmr-kb & 1551.10 & 5.23 & 250.00 & 1306.86 & 13.07 \\
\hline 10 & klmr-pmk & 4661.84 & 15.71 & 0.00 & 0.00 & 0.00 \\
\hline 11 & klmr-sb & 85.06 & 0.29 & 150.00 & 43.00 & 0.43 \\
\hline 12 & klmr-sw & 3276.40 & 11.04 & 75.00 & 828.15 & 8.28 \\
\hline 13 & klmr-swtd & 2434.27 & 8.20 & 75.00 & 615.29 & 6.15 \\
\hline 14 & klmr-tg & 16429.63 & 55.37 & 150.00 & 8305.57 & 83.06 \\
\hline & luas total & 29672.18 & 100.00 & & 11292.40 & 112.92 \\
\hline
\end{tabular}

Sumber: data primer, 2013. 
(3)Dari analisis neraca air secara meteorologis dapat disimpulkan bahwa ketersediaan air dari curah hujan di wilayah ini termasuk cukup tinggi, sehingga memungkinkan untuk dimanfaatkan untuk pemenuhan kebutuhan air, terutama untuk kebutuhan air tanaman dan kebutuhan air domestik. Dalam setiap tahun ada 7-8 bulan yang surplus. Khusus untuk kebutuhan air tanaman dalam kondisi tidak ada surplus, tetapi bukan defisit, maka yang digunakan oleh tanaman adalah lengas tanah (soil moisture).

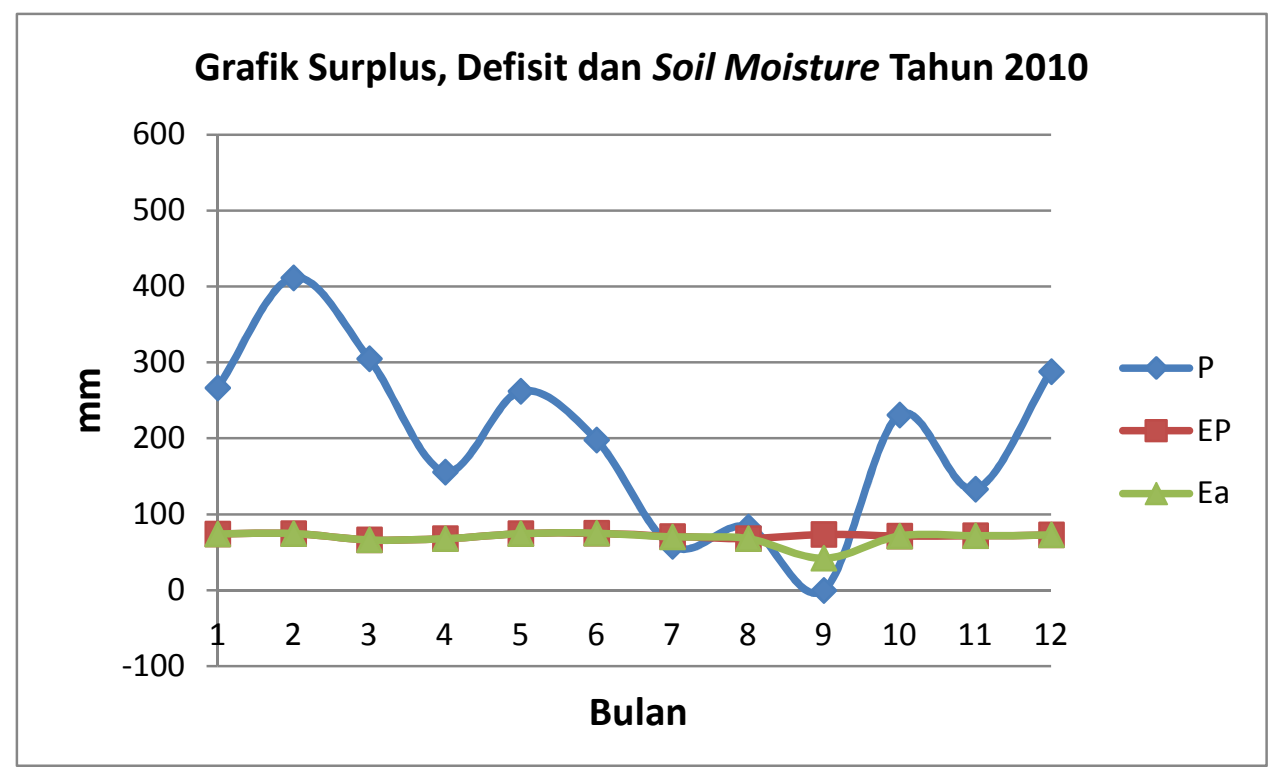

Gambar 4. Grafik surplus deficit dan Tahun 2010

(4). Perhitungan besarnya ketersediaan air di wilayah penelitian ini dihitung dengan terlebih dahulu mengetahui seluruh nilai untuk parameter yang menentukannya, yaitu luas wilayah penelitian untuk masing-masing penggunaan lahan, persentase aliran, surplus air dan aliran mantapnya. Untuk formasi bentuklahan karst, digunakan asumsi persentase aliran sebesar 25\% (Notodiharjo, 1982, dalam Langi, 2007). Besarnya aliran mantap diketahui dengan mengalikan persentase aliran dengan total surplus air tahunan. Data ketersediaan dan kebutuhan air dapat dilihat pada Tabel 5 dan 6 . 
Dampak Perubahan Iklim Terhadap Imbangan Air Secara Meteorologis Dengan Menggunakan Metode Thornthwaite Mather Untuk Analisis Kekritisan Air di Karst Wonogiri

Tabel 4. Perhitungan Nilai Parameter Penentuan Neraca Air di Wilayah Penelitian Tahun 2010

\begin{tabular}{|c|c|c|c|c|c|c|c|c|c|c|c|c|c|}
\hline Bulan & Jan & Feb & Mar & Apr & Mei & Jun & Jul & Agt & Sep & 0kt & Nov & Des & Total \\
\hline T (oC) & 29,025 & 28,125 & 29,625 & 30,025 & 26,315 & 25,815 & 30,625 & 34,525 & 30,025 & 30,125 & 29,825 & 27,385 & 351,44 \\
\hline P (mm/bulan) & 266,50 & 411,50 & 305,00 & 156,00 & 262,00 & 198,00 & 58,00 & 83,50 & 0,00 & 231,00 & 133,00 & 288,00 & 2392,50 \\
\hline EP (mm/bulan) & 73,89 & 74,66 & 66,24 & 67,80 & 74,51 & 74,98 & 70,94 & 67,94 & 73,43 & 71,33 & 71,58 & 72,64 & 859,93 \\
\hline P-EP & 192,61 & 336,84 & 238,76 & 88,20 & 187,49 & 123,02 & $-12,94$ & 15,56 & $-73,43$ & 159,67 & 61,42 & 215,36 & 1532,57 \\
\hline APWL & 0 & 0 & 0 & 0 & 0 & 0 & 12,94 & 28,50 & 101,93 & 261,60 & 0 & 0 & 404,97 \\
\hline Sto & 112,92 & 112,92 & 112,92 & 112,92 & 112,92 & 112,92 & 112,92 & 112,92 & 112,92 & 112,92 & 112,92 & 112,92 & 1355,04 \\
\hline St & 112,92 & 112,92 & 112,92 & 112,92 & 112,92 & 112,92 & 100,70 & 87,73 & 45,79 & 11,14 & 112,92 & 112,92 & 1148,72 \\
\hline St & 0 & 0 & 0 & 0 & 0 & 0,00 & 12,22 & 12,96 & 41,94 & 34,66 & $-101,78$ & 0 & 0,00 \\
\hline Ea (mm/bulan) & 73,89 & 74,66 & 66,24 & 67,80 & 74,51 & 74,98 & 70,22 & 67,94 & 41,94 & 71,33 & 71,58 & 72,04 & 827,73 \\
\hline S & 192,61 & 336,84 & 238,76 & 88,20 & 187,49 & 0,00 & 0,00 & 0,00 & 0,00 & 0,00 & 163,20 & 215,36 & 1422,46 \\
\hline D & 0,00 & 0,00 & 0,00 & 0,00 & 0,00 & 0,00 & 0,71 & 0,00 & 31,49 & 0,00 & 0,00 & 0,00 & 32,20 \\
\hline
\end{tabular}

Sumber: pengolahan data primer, 2013.

Tabel 5. Kebutuhan Air Domestik dan Kebutuhan Air untuk Tanaman di Wilayah Penelitian tahun 2012.

\begin{tabular}{|l|l|r|}
\hline \multicolumn{3}{|l|}{ Tabel Kebutuhan Air Domestik dan Tanaman } \\
\hline No & Jenis Penggunaan & Kebutuhan Air (It/thn) \\
\hline 1 & Domestik & 4487404608 \\
\hline 2 & Tanaman & 7178580000 \\
\hline & Total & 11665984608 \\
\hline
\end{tabular}

Sumber: pengolahan data primer, 2013

Tabel 6. Penentuan Nilai Indeks Kekritisan Air di Wilayah

Penelitian Tahun 2012

\begin{tabular}{|l|l|}
\hline \multicolumn{1}{|c|}{ Parameter } & \multicolumn{1}{c|}{ Nilai } \\
\hline Luas Karst & 55294 \\
\hline \%Aliran & 0,25 \\
\hline Surplus & 1422 \\
\hline Aliran Mantab & 355,5 \\
\hline Ketersediaan Air & 19657017 \\
\cline { 2 - 2 } & $19657017 \mathrm{~m} 3 /$ th \\
\cline { 2 - 2 } & $19657017000 \mathrm{It} / \mathrm{thn}$ \\
\hline Kebutuhan Air & $11665984608 \mathrm{It} / \mathrm{thn}$ \\
\hline Indeks kekritisan & $\mathbf{0 , 5 9 3 4 7 6 8 5 4}$ \\
\hline
\end{tabular}

Sumber: pengolahan data primer, 2013

Dari Tabel 6. ditemukan besarnya nilai indeks kekritisan air di wilayah penelitian adalah sebsar 0,59 yang menunjukkan bahwa kondisi neraca air secara meteorologis di wilayah ini termasuk mendekati kritis. Hal ini sudah harus mulai menjadi fokus perhatian untuk segera ditindaklanjuti dengan adanya penelitian terbaru di wilayah ini mengenai porositas sekunder karst yang meningkat akibat perubahan iklim. Asumsi dasar yang mengatakan bahwa 25\% dari total curah hujan di daerah karst akan menjadi limpasan 


\section{KESIMPULAN}

Hasil penelitian yang diperoleh adalah: (1) Kondisi curah hujan tahunan di Karst Wonogiri masih termasuk kategori sedang, dengan tebal hujan tahunan bisa mencapai $2000 \mathrm{~mm}$. Fluktuasi curah hujan tahunan tidak terlalu tinggi (200-500 mm per tahun); (2) Perhitungan nilai WHC sebesar 112,92 menunjukkan bahwa kemampuan lahan di wilayah penelitian untuk menyimpan dan mengikat air termasuk rendah yang disebabkan oleh jenis tanah yang ada memiliki solum tanah dangkal hingga sedang serta struktur tanah kersai dan pasiran. Jenis vegetasi penutup yang berupa palawija dengan zone parakaran dangkal juga mempengaruhi besarnya nilai WHC; (3) Analisis neraca air secara meteorologis dapat disimpulkan bahwa ketersediaan air dari curah hujan di wilayah ini termasuk cukup tinggi dengan 7-8 bulan yang surplus dan (4) Indeks kekritisan Air mempunyai nilai 0,59 yang termasuk dalam mendekati kritis.

\section{UCAPAN TERIMA KASIH}

Penelitian ini dibiayai Oleh Dana BOPTN Universitas Sebelas Maret Nomor: 165/UN27.11/PN/2003 Tanggal 10 Juni 2013

\section{DAFTAR PUSTAKA}

Darmanto, D. 1996, Hydrological Aspect of Land Use, Lecture Note, GMU - Bakosurtanal, Yogyakarta

David D. Houghton. 2007. Global Climate Change Basics, Challenges, and International Impacts. Atmospheric \& Oceanic Sciences UW - Brewer Public Library Richland Center, Madison

Dipayana, G.A; Cahyadi, A. dan Nurjani, E. 2012, Analisis Trend Kejadian Kekeringan di Sebagian Wilayah Propinsi D.I. Yogyakarta dan Dampak El-Nino Terhadapnya, Prosiding Seminar Nasional Penginderaan Jauh dan Sistem Informasi Geografis, 21 Januari 2012, Fakultas Geografi Universitas Muhammadiyah Surakarta

Eitzinger, J. 2003, A Simulation study of the effect of soil water balance and water stress on winter wheat production under different climate change scenarios, Agriculture Water Management Journal 61: 195-217

Ford, D.C., P.W., 1989, Karst Geomorphology and Hydrology, Unwin Hyman, London IPCC, 2007. Climate Change 2007: The Physical Sciense Basis. Cambridge Univ. Jennings, 1971, Karst Geomorphology, 2nd Editon, Brasil Blackwell Inc: New York Langi, O.A., 2006, Analisis Neraca Air Meteorologi untuk Kekritisan DAS pada Karakteristik Bentuklahan Karst dan Vulkanik, Tesis, YGM, Yogyakarta

Leavesley, George H, 1994, Modelling the effects of climate change on water resources-a review, Climate Change Journal 28: 159-177, Netherland

Linsley, 1949, Applied Hydrology, Mc. Groow Hill Book Company, New York

Middelkoop, et all, 2001, Impact of climate change on hydrological regimes and water resources management in the rhine basin, Journal of Climate Change 49: 105-128, Netherland

Sriharto, 1993, Analisis Hidrologi, PT Gramedia Pustaka Utama, Jakarta 
Dampak Perubahan Iklim Terhadap Imbangan Air Secara Meteorologis Dengan Menggunakan Metode Thornthwaite Mather Untuk Analisis Kekritisan Air di Karst Wonogiri

Sosrodarsono, S dan Takeda, K., 1993, Hidrologi untuk Pengairan, PT Pradnya Paramita Jakarta

Sudarmadji, Suprayogi, S., Setiadi, 2012, Konservasi Mataair Berbasis Masyarakat di Kabupaten Gunungkidul, Sekolah Pascasarjana UGM, Yogyakarta

Thornthwaite, C.W. and J.R. Matrher, 1957 Introduction and Tables for Computing Potensial Evapotranspiration and The water Balance, Publ. In Clim. Vol. X No 3 Certerton, New Jersey

Wijayanti, P. 2010, Analisis Neraca Air secara Meteorologis dengan Metode Thorntwhite Matter di DAS Alang Kabupaten Wonogiri, Jurnal MIPS, P.IPS, FKIP UNS, Surakarta

Yeuyanan, F., 2005 Kajian Neraca Air Meteorologi di Daerah Tangkapan Air Gajah Mungkur Kabupaten Wonogiri, Skripsi, UGM, Yogyakarta

Liu, Z., Yuan D., Dreybrodt W., 2005, Comparative of study Dissolution Rate-Determining Mechanisma of Limestone and Dolomete, Journal of Enviromment Geology 49' 274 $-279$ 